\title{
Recurrent thunderclap headaches from reversible cerebral vasoconstriction syndrome associated with duloxetine, xylometazoline and rhinitis medicamentosa
}

\author{
Hoang Pham MD, Stéphanie Gosselin-Lefebvre MD, Persia Pourshahnazari MD, Samuel Yip MD PhD
}

Cite as: CMAJ 2020 November 9;192:E1403-6. doi: 10.1503/cmaj.201234

A 52-year-old woman presented to the emergency department with 2 episodes of thunderclap headaches separated by about 8 hours, both occurring during defecation. She had a history of chronic nasal congestion, asthma, chronic back pain, and low mood without other major depressive features or suicidality. She had no history of hypertension. Her medications consisted of a budesonide-formoterol inhaler, salbutamol taken as needed, duloxetine $60 \mathrm{mg} / \mathrm{d}$ (a serotoninnorepinephrine reuptake inhibitor [SNRI]) and xylometazoline topical nasal decongestant spray taken once daily. The patient described periodic worsening of nasal congestion, which led her to increase her xylometazoline dosage. At the time of presentation, she was using the nasal decongestant 2-3 times daily and she had been taking duloxetine daily for 1.5 years. She did not have a history of tobacco smoking, problem drinking or recreational substance use.

On examination, she was hypertensive at 215/108 $\mathrm{mm} \mathrm{Hg}$, but after receiving analgesia, antiemetics and fluids, her blood pressure improved to $155 / 90 \mathrm{~mm} \mathrm{Hg}$. She had a Glasgow Coma Scale score of 15 , a supple neck, and no associated focal neurologic deficits, seizure activity or encephalopathy. She had severe inferior nasal turbinate hypertrophy; hyperemic nasal mucosa; minimal thin, clear secretions; and moderate right nasal septal deviation without septal perforation.

Initial computed tomography (CT) of the head and CT angiography showed small areas of convexal subarachnoid hemorrhage as well as multifocal mild-to-moderate narrowing in the intracranial arteries of the anterior and posterior circulation with a string-of-beads appearance (Figure 1). The patient's presentation was compatible with reversible cerebral vasoconstriction syndrome given the history of recurrent thunderclap headaches, triggered by a Valsalva effect from straining, exposure to 2 vasoconstrictive medications, and classic imaging findings of widespread symmetric cerebral artery narrowing and small atraumatic convexal subarachnoid hemorrhage. The term "convexal" denotes a hemorrhage distribution limited to convexities of the brain without involving adjacent brain parenchyma or extending

\section{KEY POINTS}

- Thunderclap headaches warrant emergent evaluation for aneurysmal subarachnoid hemorrhage and reversible cerebral vasoconstriction syndrome, which are the 2 most common causes.

- The most common cause of atraumatic convexal subarachnoid hemorrhage in patients aged 60 years or younger is reversible cerebral vasoconstriction syndrome.

- Exposure to vasoactive substances (e.g., adrenergic agonists and serotonergic medications) is a known risk factor for reversible cerebral vasoconstriction syndrome; multiple concomitant exposures may interact additively to further increase the risk of reversible cerebral vasoconstriction syndrome.

- All patients taking nasal decongestants should be counselled about the risk of rhinitis medicamentosa if nasal decongestants are used regularly for more than 3-5 days and the risk of reversible cerebral vasoconstriction syndrome, especially if there are concomitant exposures to vasoactive substances.

into interhemispheric fissures, basal cisterns or ventricles. Computed tomography and $\mathrm{CT}$ angiography were adequate noninvasive investigations in this case, because of the convexal pattern of the subarachnoid hemorrhage. We did not do a lumbar puncture, which is reserved for investigating thunderclap headache in the setting of a normal CT to exclude a small subarachnoid hemorrhage without an aneurysm seen on CT angiography. ${ }^{1}$

We tapered the duloxetine $60 \mathrm{mg} / \mathrm{d}$ down to $30 \mathrm{mg}$ every other day for 3 doses and stopped, after confirming that her primary indication was for sciatica, which was well controlled. We also weaned and discontinued the xylometazoline, and given the patient's severe nasal congestion and comorbid asthma, we prescribed montelukast $10 \mathrm{mg} / \mathrm{d}$ along with beclomethasone nasal spray $50 \mu \mathrm{g}, 2$ sprays each nostril daily, as an effective and safer long-term option for her nasal congestion related to suspected allergic rhinitis. We discussed the rationale for using intranasal steroids rather than decongestant sprays. Finally, to 


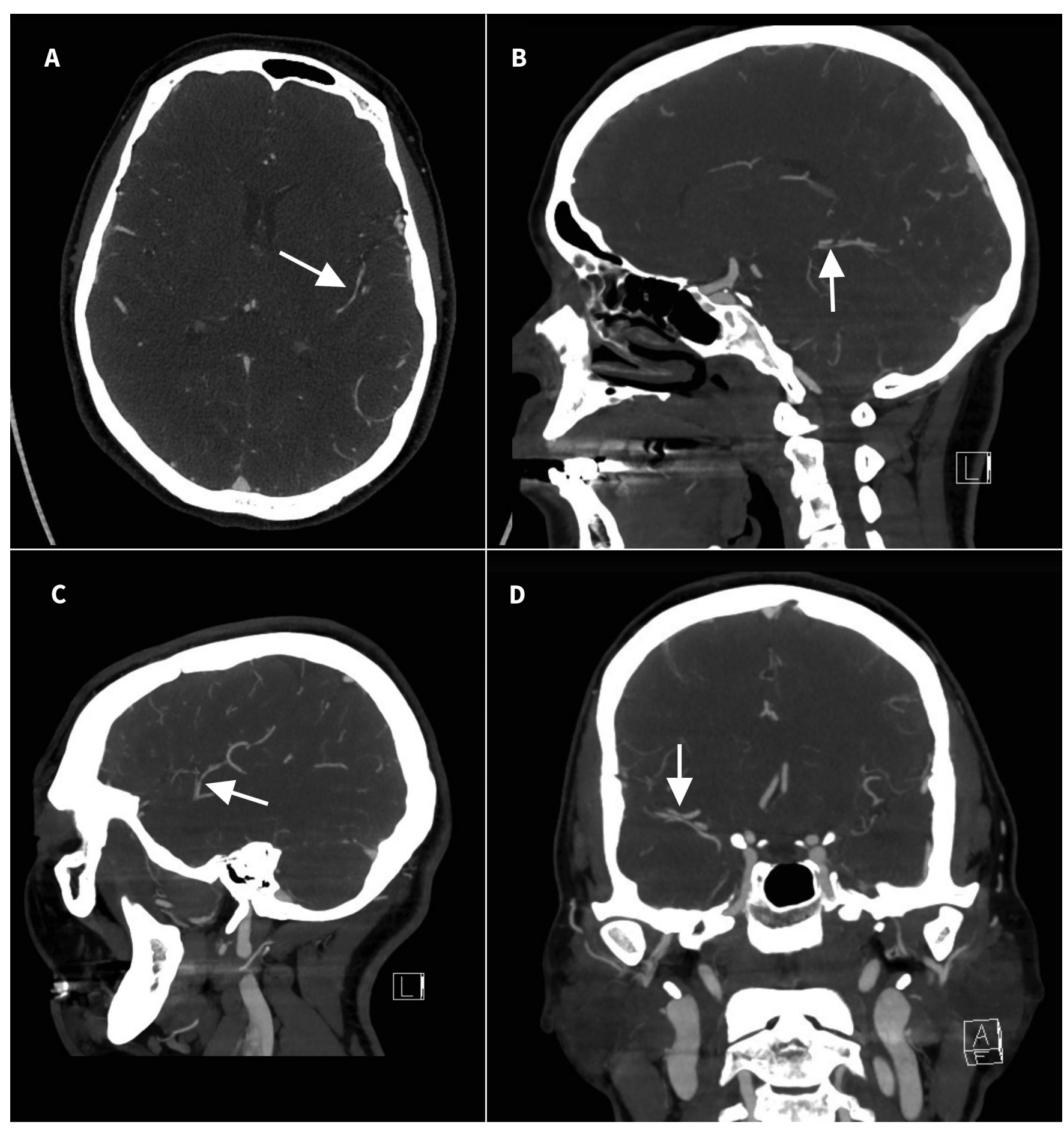

Figure 1: Computed tomography angiogram of the head in a 52-year-old woman who presented to the emergency department with 2 episodes of thunderclap headaches, showing multifocal segmental mild-to-moderate stenoses bilaterally in the circle of Willis and its branches in both anterior and posterior circulation. Colloquially, this creates a "string-of-beads" appearance (arrows). (A) Axial, (B,C) sagittal and (D) coronal views.

hasten reversal of the cerebral vasoconstriction, we admitted the patient and started treatment with verapamil immediate release, a calcium channel blocker, $120 \mathrm{mg}$ orally every 8 hours. After 2 weeks of therapy, we ordered repeat imaging to verify angiographic stability before discharge. It showed resolved subarachnoid hemorrhage and mild interval improvement in the intracranial arterial stenoses in the bilateral anterior, middle and posterior cerebral arteries. We discharged the patient taking verapamil extended release $180 \mathrm{mg}$ twice daily with followup in the stroke prevention clinic, and we advised her to avoid nasal decongestants, serotonergic antidepressants and other vasoactive drugs such as dihydroergotamine and triptans, if possible. She has had no further episodes of headache as of last follow-up. 
After her hospital stay, our patient also saw an allergist, who used specific immunoglobulin E testing to identify an allergy to cats. Thus, her year-round congestion could be attributed to her pet cat. Although we recommended that she completely avoid contact with her cat, she was not ready and opted for subcutaneous immunotherapy. She was further assessed by an otolaryngologist to identify nonallergic factors contributing to severe chronic nasal congestion, with consideration of nasal septal correction and turbinate reduction.

\section{Discussion}

\section{Reversible cerebral vasoconstriction syndrome versus aneurysmal subarachnoid hemorrhage}

The term thunderclap headache describes a headache that reaches maximal intensity at onset. The 2 most common and urgent causes of thunderclap headache to consider are reversible cerebral vasoconstriction syndrome and aneurysmal subarachnoid hemorrhage (Box 1). A prospective study involving 173 patients with reversible cerebral vasoconstriction syndrome found that $71 \%$ were female, $32 \%$ had a history of migraines, $49 \%-60 \%$ were exposed to vasoactive substances and $8 \%-12 \%$ were postpartum. ${ }^{2}$ The authors found that thunderclap headache was present in $94 \%$ and tended to be recurrent $(87 \%)$ and provoked (77\%), and associated with sexual intercourse (27\%), exertion (22\%) or acute emotional stress (19\%). ${ }^{2}$ Other reported associations include defecation, urination, cough, sneezing, bathing or showering. ${ }^{3}$ Differentiating reversible cerebral vasoconstriction syndrome from aneurysmal subarachnoid hemorrhage is essential, and we consulted the on-call neurosurgeon, who concluded that, based on the patient's convexal subarachnoid hemorrhage pattern and multifocal multivessel narrowing, reversible cerebral vasoconstriction syndrome was the most likely diagnosis, not subarachnoid hemorrhage related to a ruptured aneurysm. In patients aged 60 years or younger, the most common cause of atraumatic convexal subarachnoid hemorrhage is reversible cerebral vasoconstriction syndrome. ${ }^{4}$

\section{Risk factors for reversible cerebral vasoconstriction syndrome}

Reversible cerebral vasoconstriction syndrome has a long list of putative risk factors without a fully unifying mechanism; however, drugs and conditions associated with vasoconstriction have been most consistently observed. Two prospective cohort studies identified the postpartum state and exposure to at least 1 vasoactive substance as risk factors. ${ }^{2,3}$ The top 3 vasoactive substances were cannabis $(20 \%-32 \%)$, selective serotonin reuptake inhibitors (SSRIs) (13\%-21\%) and nasal decongestants $(13 \%) .^{2,3}$ Other less common vasoactive substances included alcohol (binge drinking), cocaine, corticosteroids, interferon- $\alpha$, nicotine patches, ergots, triptans, SNRIs, epinephrine, cyclosporine and sulprostone. ${ }^{2,3}$ Exposure to a single vasoactive substance was observed in 39\%, and multiple exposures were documented in $14.5 \%$ of cases. ${ }^{3}$ The most common multiple exposures involved cannabis with alcohol binge drinking (6\%) or cannabis with a nasal decongestant (3\%); an SSRI combined with
Box 1: Comparison of aneurysmal subarachnoid hemorrhage and reversible cerebral vasoconstriction syndrome ${ }^{1-9}$

\begin{tabular}{|c|c|c|}
\hline Characteristic & Aneurysmal SAH & RCVS \\
\hline \multicolumn{3}{|l|}{ Epidemiology } \\
\hline Incidence & - 3-25/100000 & - Unknown \\
\hline Age, yr & $\begin{array}{l}\text { - } 40-60 \\
\text { - Peak } 50\end{array}$ & $\begin{array}{l}\text { - } 10-76 \\
\text { - Mean 40-45 }\end{array}$ \\
\hline $\begin{array}{l}\text { Sex, female-to- } \\
\text { male ratio }\end{array}$ & $\begin{array}{l}\text { - Female > male after } \\
\text { fifth decade (1.6) }\end{array}$ & - Female $>$ male, 2 to $10: 1$ \\
\hline \multicolumn{3}{|c|}{ Clinical features } \\
\hline Risk factors & $\begin{array}{l}\text { - Hypertension } \\
\text { - Cigarette smoking } \\
\text { - Family history/genetic } \\
\text { - Alcohol } \\
\text { - Sympathomimetic } \\
\text { drugs }\end{array}$ & $\begin{array}{l}\text { - }>60 \% \text { of cases with } \\
\text { identifiable risk factor }\end{array}$ \\
\hline $\begin{array}{l}\text { Headache } \\
\text { features }\end{array}$ & $\begin{array}{l}\text { - Single thunderclap } \\
\text { headache } \\
\text { - Sentinel headache } \\
(10 \%-43 \%) \\
\text { - Longer duration }\end{array}$ & $\begin{array}{l}\text { - Recurrent thunderclap } \\
\text { headache (mean of } 4 \text { ) } \\
\text { - Short duration } 1-3 \mathrm{~h}\end{array}$ \\
\hline $\begin{array}{l}\text { Physical } \\
\text { examination }\end{array}$ & $\begin{array}{l}\text { - Altered level of } \\
\text { consciousness } \\
\text { - Focal neurologic } \\
\text { deficit } \\
\text { - Seizure }\end{array}$ & $\begin{array}{l}\text { - More often normal } \\
\text { - Focal neurologic deficit } \\
\text { (if associated with } \\
\text { stroke) } \\
\text { - Seizure }\end{array}$ \\
\hline
\end{tabular}

Imaging and other tests

$\begin{array}{ll}\text { Brain imaging } & \text { Perisylvian SAH } \\ & \text { Perimesencephalic } \\ & \text { subarachnoid } \\ & \text { intraparenchymal } \\ & \text { hemorrhage, subdural } \\ & \text { hemorrhage, } \\ & \text { intraventricular } \\ & \text { hemorrhage }\end{array}$

- Atraumatic convexal SAH

- $\operatorname{Normal}(30 \%-70 \%)$

- Ischemia

- Lobar hemorrhage

- Posterior reversible encephalopathy syndrome signs (i.e., bilateral areas of subcortical white matter vasogenic edema in posterior cerebral hemispheres, often apparent on CT head, but seen better on MRI)

Vascular
imaging

- Multifocal segmental cerebral vasoconstriction (string and beads)

- Reversible within 3 mo

$\begin{array}{ll}\text { Lumbar } & \text { - Elevated erythrocytes } \\ \text { puncture } & \text { (from tube 1 to 4) } \\ & \text { - Positive } \\ & \text { xanthochromia } \\ & \text { - Elevated opening } \\ & \text { pressure }\end{array}$

- Normal or mild elevated white cells and or protein

Prognosis

$\begin{array}{ll}\text { Mortality and } & \text { - } \begin{array}{l}\text { Mortality rate } 8 \%-67 \% \\ \text { (median mortality rate } \\ \text { morbidity }\end{array} \\ & \begin{array}{l}\text { - } \\ \text { Rate of persistent } \\ \text { dependence } 8 \%-20 \%\end{array} \\ \text { Recurrence } & -2.2 \% \text { at } 10 \mathrm{yr}\end{array}$

- $<5 \%$ with lifethreatening form of RCVS

- $<15 \%-20 \%$ mild deficit

- Recurrence in 5\%-6\% at $3.4 \mathrm{yr}$ 
a nasal decongestant was observed in $1 \%$ of cases. ${ }^{3}$ Our patient's new-onset recurrent thunderclap headaches associated with increased use of xylometazoline and chronic use of duloxetine was highly suspicious for reversible cerebral vasoconstriction syndrome. Similar to our case, Loewen and colleagues described a 31-year-old woman with thunderclap headache associated with chronic use of oxymetazoline, another topical nasal decongestant spray, and sertraline, an SSRI. ${ }^{5}$ The patient had clinical and radiologic resolution after stopping oxymetazoline and receiving treatment with nimodipine, a calcium channel blocker. ${ }^{5}$

\section{Management of reversible cerebral vasoconstriction syndrome}

No randomized controlled trials have been conducted to guide the management of reversible cerebral vasoconstriction syndrome. The mainstay of treatment is early recognition, rest and removal of offending agents, as reversible cerebral vasoconstriction syndrome is often self-limited with no new symptoms after 4 weeks and angiographic resolution by 3 months. ${ }^{6}$ Symptomatic treatment of headache is recommended with simple analgesics, strictly avoiding triptans. High blood pressure should be treated according to current stroke guidelines, especially being mindful to avoid hypotension in the setting of cerebral vasoconstriction. ${ }^{10}$ Several case series support the use of calcium channel blockers such as nimodipine, verapamil and nicardipine to mitigate cerebral vasoconstriction in reversible cerebral vasoconstriction syndrome, consistent with the management of vasospasm in aneurysmal subarachnoid hemorrhage. ${ }^{6}$ They are well tolerated and are reasonable considerations in recurrent episodes of thunderclap headache. ${ }^{6}$

\section{Rhinitis medicamentosa as a risk factor for reversible cerebral vasoconstriction syndrome}

Along with reversible cerebral vasoconstriction syndrome, this patient was also diagnosed with rhinitis medicamentosa based on severe chronic nasal congestion and chronic xylometazoline use. Rhinitis medicamentosa is a special type of medication-induced rhinitis due to prolonged use of a topical $\alpha$-adrenergic receptor agonist (e.g., oxymetazoline, xylometazoline and phenylephrine) for more than 3-5 days. It can manifest as rebound nasal congestion, tachyphylaxis and impaired mucociliary clearance, predisposing the patient to a vicious cycle of refractory nasal congestion caused by and transiently relieved by the intranasal decongestant. By conducting a full clinical evaluation of chronic nasal obstructive symptoms, we can explore possible allergic triggers to avoid, offer patients targeted and highly effective treatments, and discuss the negative impacts of readily accessible over-the-counter nasal decongestants. Nasal decongestants when combined with other common vasoactive substances, such as serotonergic antidepressants, cannabis and alcohol (binge drinking), may increase the risk of reversible cerebral vasoconstriction syndrome. Health care professionals should be aware of these potential interactions and advise their patients accordingly.

\section{References}

1. Macdonald RL, Schweizer TA. Spontaneous subarachnoid haemorrhage. Lancet 2017;389:655-66.

2. de Boysson H, Parienti J-J, Mawet J, et al. Primary angiitis of the CNS and reversible cerebral vasoconstriction syndrome: a comparative study. Neurology 2018;91:e1468-78.

3. Ducros A, Boukobza M, Porcher R, et al. The clinical and radiological spectrum of reversible cerebral vasoconstriction syndrome. A prospective series of 67 patients. Brain 2007;130:3091-101

4. Kumar S, Goddeau RP Jr, Selim MH, et al. Atraumatic convexal subarachnoid hemorrhage: clinical presentation, imaging patterns, and etiologies. Neurology 2010;74:893-9.

5. Loewen AHS, Hudon ME, Hill MD. Thunderclap headache and reversible segmental cerebral vasoconstriction associated with use of oxymetazoline nasal spray. CMAJ 2004;171:593-4.

6. Cappelen-Smith C, Calic Z, Cordato D. Reversible cerebral vasoconstriction syndrome: recognition and treatment. Curr Treat Options Neurol 2017;19:21.

7. Rocha EA, Topcuoglu MA, Silva GS, et al. RCVS2 score and diagnostic approach for reversible cerebral vasoconstriction syndrome. Neurology 2019;92:e639-47.

8. Lawton MT, Vates GE. Subarachnoid hemorrhage. N Engl J Med 2017;377:257-66.

9. Connolly ES Jr, Rabinstein AA, Carhuapoma JR, et al.; American Heart Association Stroke Council; Council on Cardiovascular Radiology and Intervention; Council on Cardiovascular Nursing; Council on Cardiovascular Surgery and Anesthesia; Council on Clinical Cardiology. Guidelines for the management of aneurysmal subarachnoid hemorrhage: a guideline for healthcare professionals from the American Heart Association/American Stroke Association. Stroke 2012;43:1711-37.

10. Boulanger JM, Lindsay MP, Gubitz G, et al. Canadian stroke best practice recommendations for acute stroke management: prehospital, emergency department, and acute inpatient stroke care, update 2018. Int J Stroke 2018;13:949-84.

\section{Competing interests: None declared.}

This article has been peer reviewed.

The authors have obtained patient consent.

Affiliations: Division of Allergy and Immunology (Pham), Department of Medicine, McGill University Health Centre, Montréal, Que.; Division of Neurology (Gosselin-Lefebvre), Centre hospitalier universitaire de Québec-Hôpital de l'Enfant-Jésus, Université Laval, Québec, Que.; Division of Allergy and Immunology (Pourshahnazari), University of British Columbia; Division of Neurology (Yip), Vancouver General Hospital, University of British Columbia, Vancouver, BC

Contributors: Hoang Pham and Stéphanie Gosselin-Lefebvre drafted the manuscript and all authors revised it critically for important intellectual content. All authors approved the final version to be published and agreed to act as guarantors of the work.

Correspondence to: Hoang Pham, hoang.pham2@mail.mcgill.ca

The section Cases presents brief case reports that convey clear, practical lessons. Preference is given to common presentations of important rare conditions, and important unusual presentations of common problems. Articles start with a case presentation (500 words maximum), and a discussion of the underlying condition follows (1000 words maximum). Visual elements (e.g., tables of the differential diagnosis, clinical features or diagnostic approach) are encouraged. Consent from patients for publication of their story is a necessity. See information for authors at www.cmaj.ca. 